\title{
Impact of COVID-19 pandemic on central-line-associated bloodstream infections during the early months of 2020, National Healthcare Safety Network
}

\author{
Prachi R. Patel $\mathrm{MPH}^{1,2}$ (1) , Lindsey M. Weiner-Lastinger $\mathrm{MPH}^{1}$, Margaret A. Dudeck MPH ${ }^{1}$, Lucy V. Fike MPH ${ }^{1}$, \\ David T. Kuhar MD ${ }^{1}$, Jonathan R. Edwards MStat ${ }^{1}$, Daniel Pollock MD ${ }^{1}$ and Andrea Benin MD ${ }^{1}$ \\ ${ }^{1}$ Division of Healthcare Quality Promotion, Centers for Disease Control and Prevention, Atlanta, Georgia and ${ }^{2} \mathrm{CACl}$, Atlanta, Georgia
}

\begin{abstract}
Data reported to the Centers for Disease Control and Prevention's National Healthcare Safety Network (CDC NHSN) were analyzed to understand the potential impact of the COVID-19 pandemic on central-line-associated bloodstream infections (CLABSIs) in acute-care hospitals. Descriptive analysis of the standardized infection ratio (SIR) was conducted by location, location type, geographic area, and bed size.
\end{abstract}

(Received 4 March 2021; accepted 5 March 2021; electronically published 15 March 2021)

The US Centers for Disease Control and Prevention's (CDC) National Healthcare Safety Network (NHSN) is the nation's surveillance system for healthcare-associated infections (HAIs). Hospitals and public health organizations track HAIs using the standardized infection ratio (SIR), and the Centers for Medicare and Medicaid Services (CMS) require submission of data on HAIs to the NHSN for payment programs such as the Hospital-Acquired Conditions Reporting Program (HACRP). ${ }^{1}$ From 2015 to 2019 , there was a $31 \%$ decline in the national SIR for central-line-associated bloodstream infections (CLABSIs). ${ }^{2}$ However, in the face of the coronavirus disease 19 (COVID-19) pandemic, HAIs in hospitals may have increased. ${ }^{3},{ }^{4}$ To understand the impact of the early months of the COVID-19 pandemic on CLABSIs nationally, SIRs for the second quarter of 2020 (2020 Q2: April, May, June) were compared to those from 2019 Q2.

\section{Methods}

Reporting on CLABSIs to the NHSN should occur in any inpatient location where data on central lines can be collected, including intensive care units (ICUs), specialty care areas (SCAs), neonatal intensive care units (NICUs), and wards. ${ }^{5}$ In this analysis, we included data as of January 1, 2021, from acute-care hospitals (ACHs) for 2019 Q2 and 2020 Q2. Only locations that had continuous and consistent reporting, defined as ACHs reporting all 3 months of CLABSI data for the same location in both 2019 Q2 and 2020 Q2, were included. SIRs were calculated by dividing the number of observed infections by the predicted number determined from the logistic regression model generated from national data during a baseline period. ${ }^{6} \mathrm{~A}$ mid- $P$ exact test

\footnotetext{
Author for correspondence: Prachi R. Patel. E-mail: ywt5@cdc.gov

Cite this article: Patel PR, et al. (2022). Impact of COVID-19 pandemic on centralline-associated bloodstream infections during the early months of 2020, National Healthcare Safety Network. Infection Control \& Hospital Epidemiology, 43: 790-793, https://doi.org/10.1017/ice.2021.108
}

was preformed to compare the 2020 Q2 SIRs to the baseline of 1 and to the 2019 Q2 SIRs. Device utilization ratios were calculated by dividing central-line days by patient days. Regions were defined by the US Department of Health and Human Services (HHS). ${ }^{7}$

Our analysis was restricted to the units included in the CMS HACRP and location types that had at least 20 reporting locations nationwide. ${ }^{1}$ Because CMS suspended the HACRP reporting requirement for HAIs during $2020 \mathrm{Q} 2$, the number of reporting hospitals in 2020 Q2 was compared to 2019 Q2.

The percentage change in the SIR was calculated as follows: [(SIR for 2020 Q2 - SIR for 2019 Q2)/SIR for 2019 Q2 × 100]. A mid-P exact test was performed to estimate the $95 \%$ confidence intervals around SIR percentage change values. The percentile distribution of 2020 Q2 SIRs included those facilities that had a denominator of the SIR (ie, number predicted CLABSI) $>1$. Percentile distributions are shown for strata with $>20$ facility-level SIRs.

\section{Results}

Our analysis included 13,136 inpatient units from 2,986 ACHs; 936 facilities had at least 1 predicted CLABSI and an SIR calculated. A $28 \%$ increase (95\% CI, 20.0-33.6) was observed in the national SIR, from 0.68 in 2019 Q2 to 0.87 in 2020 Q2 (Table 1). Device utilization increased nationally from 0.21 in 2019 Q2 to 0.23 in 2020 Q2 (data not shown).

Critical care units had the greatest percentage increase (39\%) in SIR, from 0.75 in 2019 to 1.04 in 2020. Ward locations experienced the second highest increase (13\%). Critical care locations had the highest number of CLABSIs in 2020 Q2, with 1,911 events. Hospitals in all bed-size categories exhibited an increase in SIR.

In 2020 Q2, reporting of CLABSI surveillance dropped by $17 \%$ nationally, in contrast with 2019 Q2. The greatest decrease in reporting (48\%) occurred in the Middle Northeast. Regional analysis showed significant percentage changes in the SIR from 2019 to

(c) The Author(s), 2021. Published by Cambridge University Press on behalf of The Society for Healthcare Epidemiology of America. This is an Open Access article, distributed under the terms of the Creative Commons Attribution licence (http://creativecommons.org/licenses/by/4.0/), which permits unrestricted re-use, distribution, and reproduction in any medium, provided the original work is properly cited. 


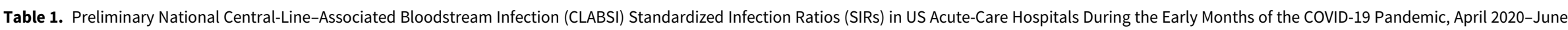
2020

\begin{tabular}{|c|c|c|c|c|c|c|c|c|c|c|c|c|c|c|c|}
\hline \multirow[t]{2}{*}{ Characteristic } & \multirow[t]{2}{*}{$\begin{array}{l}\text { Reporting Hospitals } \\
\text { in } 2020 \text { Q2 }^{\mathrm{a}}\end{array}$} & \multirow[t]{2}{*}{$\begin{array}{l}\text { Total Reporting } \\
\text { Hospitals in } 2019 \mathrm{Q}^{\mathrm{b}}\end{array}$} & \multirow[t]{2}{*}{$\begin{array}{l}\text { Observed } \\
\text { CLABSI }\end{array}$} & \multirow[t]{2}{*}{$\begin{array}{l}\text { Predicted } \\
\text { CLABSI }\end{array}$} & \multirow[t]{2}{*}{$\begin{array}{l}\text { Central- } \\
\text { Line Days }\end{array}$} & \multirow[t]{2}{*}{$\begin{array}{l}2020 \\
\text { Q2 SIR }\end{array}$} & \multirow[t]{2}{*}{$\begin{array}{l}2019 \\
\text { Q2 SIR }\end{array}$} & \multirow[t]{2}{*}{$\begin{array}{l}\text { SIR } \% \\
\text { Change }^{c}\end{array}$} & \multirow[t]{2}{*}{$\begin{array}{l}\text { 95\% Confidence Interval for } \\
\text { the SIR \% Change }\end{array}$} & \multicolumn{6}{|c|}{$\begin{array}{l}\text { Facility-Level Distribution of the } \\
\text { Standardized Infection Ratio (SIR) } \\
\text { for } 2020 \mathrm{Q}^{\mathrm{d}}\end{array}$} \\
\hline & & & & & & & & & & $10 \%$ & $25 \%$ & $50 \%$ & $75 \%$ & $90 \%$ & $100 \%$ \\
\hline All Hospitals & 2,986 & 3,594 & 2,887 & $3,334.17$ & $3,302,324$ & $0.87^{e}$ & $0.68^{\mathrm{e}}$ & $28.0^{f}$ & (20.0 to 33.6 ) & 0.00 & 0.00 & 0.68 & 1.17 & 1.96 & 6.72 \\
\hline \multicolumn{16}{|l|}{ Location type } \\
\hline $\mathrm{CC}$ & 2,513 & 3,070 & 1,911 & $1,836.02$ & $1,707,981$ & 1.04 & $0.75^{\mathrm{e}}$ & $38.7^{f}$ & (29.2 to 48.5 ) & 0.00 & 0.00 & 0.78 & 1.51 & 2.31 & 6.49 \\
\hline CC_ONC & 19 & 21 & 10 & 10.93 & 10,706 & 0.91 & 1.08 & -15.7 & $(-63.2$ to 89.6$)$ & $\ldots$ & $\ldots$ & $\ldots$ & $\ldots$ & $\ldots$ & $\ldots$ \\
\hline NICU & 812 & 1,035 & 162 & 305.93 & 219,115 & $0.53^{\mathrm{e}}$ & $0.65^{\mathrm{e}}$ & -18.5 & $(-33.4$ to 0.5$)$ & 0.00 & 0.00 & 0.00 & 0.80 & 1.26 & 2.56 \\
\hline Wardg & 2,852 & 3,478 & 804 & $1,181.29$ & $1,364,522$ & $0.68^{\mathrm{e}}$ & $0.60^{\mathrm{e}}$ & $13.3^{f}$ & (2.3 to 23.9 ) & 0.00 & 0.00 & 0.51 & 0.99 & 1.81 & 7.89 \\
\hline \multicolumn{16}{|l|}{ Bed size } \\
\hline$<100$ beds & 1,117 & 1,341 & 114 & 124.46 & 180,626 & 0.92 & $0.66^{e}$ & $39.4^{f}$ & (4.2 to 82.7 ) & $\ldots$ & $\ldots$ & $\ldots$ & $\ldots$ & $\ldots$ & $\ldots$ \\
\hline $100-199$ beds & 774 & 921 & 418 & 429.09 & 520,542 & 0.97 & $0.74^{e}$ & $31.1^{f}$ & (14.2 to 52.7 ) & 0.00 & 0.00 & 0.77 & 1.56 & 2.42 & 6.24 \\
\hline 200-299 beds & 474 & 553 & 505 & 594.21 & 612,958 & 0.85 & $0.66^{\mathrm{e}}$ & $28.8^{f}$ & (13.0 to 46.7$)$ & 0.00 & 0.00 & 0.62 & 1.08 & 2.01 & 6.72 \\
\hline $300-499$ beds & 426 & 536 & 820 & $1,030.37$ & 956,115 & $0.80^{\mathrm{e}}$ & $0.62^{\mathrm{e}}$ & $29.0^{f}$ & (15.6 to 41.5$)$ & 0.00 & 0.00 & 0.64 & 1.20 & 1.99 & 4.76 \\
\hline 500-699 beds & 123 & 156 & 549 & 620.14 & 557,211 & 0.89 & $0.68^{\mathrm{e}}$ & $30.9^{f}$ & (15.7 to 48.3 ) & 0.14 & 0.39 & 0.73 & 1.11 & 1.74 & 4.31 \\
\hline$>700$ beds & 72 & 88 & 481 & 535.91 & 474,872 & 0.90 & $0.80^{\mathrm{e}}$ & 12.5 & $(-0.8$ to 27.9$)$ & 0.30 & 0.50 & 0.85 & 1.14 & 1.70 & 2.17 \\
\hline \multicolumn{16}{|l|}{ HHS Region } \\
\hline $\begin{array}{l}1 \text { - Upper } \\
\text { Northeast }\end{array}$ & 116 & 147 & 137 & 128.45 & 133,833 & 1.07 & $0.74^{e}$ & $44.6^{f}$ & (11.3 to 88.4 ) & 0.00 & 0.00 & 0.92 & 1.19 & 2.72 & 4.48 \\
\hline $\begin{array}{l}2 \text { - Middle } \\
\text { Northeast }\end{array}$ & 131 & 254 & 111 & 159.39 & 162,136 & $0.70^{\mathrm{e}}$ & $0.67^{\mathrm{e}}$ & 4.5 & $(-20.0$ to 36.6$)$ & 0.00 & 0.00 & 0.42 & 1.31 & 1.86 & 3.46 \\
\hline $\begin{array}{l}3 \text { - Lower } \\
\text { Northeast }\end{array}$ & 286 & 336 & 357 & 379.91 & 368,526 & 0.94 & $0.70^{\mathrm{e}}$ & $34.3^{f}$ & (14.4 to 56.3 ) & 0.00 & 0.00 & 0.70 & 1.14 & 1.99 & 3.83 \\
\hline 4 - Southeast & 694 & 786 & 660 & 802.99 & 786,484 & $0.82^{\mathrm{e}}$ & $0.72^{\mathrm{e}}$ & $13.9^{f}$ & (2.0 to 26.9 ) & 0.00 & 0.12 & 0.65 & 1.07 & 1.89 & 6.72 \\
\hline 5 - Great Lakes & 460 & 576 & 498 & 525.58 & 514,927 & 0.95 & $0.71^{\mathrm{e}}$ & $33.8^{f}$ & (16.7 to 51.7 ) & 0.00 & 0.00 & 0.67 & 1.40 & 1.97 & 4.82 \\
\hline 6 - South Central & 494 & 597 & 366 & 442.18 & 442,148 & $0.83^{e}$ & $0.76^{e}$ & 9.2 & ( -6.2 to 25.4$)$ & 0.00 & 0.31 & 0.71 & 1.16 & 1.83 & 2.90 \\
\hline 7 - Middle Plains & 163 & 188 & 134 & 160.40 & 157,863 & $0.84^{e}$ & $0.68^{\mathrm{e}}$ & 23.5 & $(-4.1$ to 56.1$)$ & 0.00 & 0.00 & 0.75 & 1.11 & 1.91 & 2.62 \\
\hline $\begin{array}{l}8 \text { - Northern } \\
\text { Plains }\end{array}$ & 135 & 143 & 107 & 107.02 & 106,249 & 1.00 & $0.62^{\mathrm{e}}$ & $61.3^{f}$ & (19.9 to 121.2 ) & 0.00 & 0.45 & 0.81 & 1.54 & 2.18 & 2.83 \\
\hline 9 - West & 400 & 454 & 434 & 508.19 & 505,247 & $0.85^{\mathrm{e}}$ & $0.57^{\mathrm{e}}$ & $49.1^{f}$ & (30.2 to 74.7 ) & 0.00 & 0.00 & 0.63 & 1.20 & 2.28 & 4.64 \\
\hline 10 - Northwest & 105 & 112 & 82 & 119.25 & 123,656 & $0.69^{e}$ & $0.45^{\mathrm{e}}$ & $53.3^{f}$ & (10.3 to 114.6 ) & 0.00 & 0.00 & 0.61 & 1.17 & 1.90 & 2.70 \\
\hline
\end{tabular}

Note. CC, critical care; CC_ONC, oncology critical care; NICU, neonatal intensive care units; HHS, Department of Health and Human Services.

"Includes hospitals reporting three months of complete CLABSI surveillance data for the same location in both 2019 Q2 and 2020 Q2.

Includes all hospitals reporting 3 months of complete CLABSI surveillance data for 2019 Q2 (will be greater than consistent and continuous reporters).

cCalculated as follows: [(SIR for 2020 Q2 - SIR for 2019 Q2)/SIR for 2019 Q2 × 100].

dIf there were $<20$ SIRs nationally, the distribution is displayed as missing.

Significantly different from $1 ; P<.05$

Significant diference betwe 2020 Q2 and 2019 Q2 SIRs; $P<.05$

Includes the following location types: medical ward, medical surgical ward, pediatric medical surgical ward, pediatric medical ward, surgical ward, and pediatric surgical ward. 


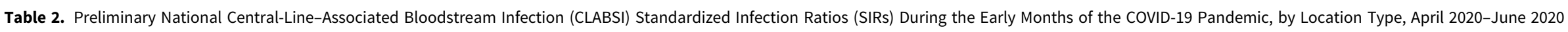

\begin{tabular}{|c|c|c|c|c|c|c|c|c|c|c|c|c|c|c|}
\hline \multirow[t]{2}{*}{ Location Type } & \multirow[t]{2}{*}{$\begin{array}{c}\text { No. of } \\
\text { Locations }\end{array}$} & \multirow[t]{2}{*}{$\begin{array}{c}\text { Observed } \\
\text { CLABSI }\end{array}$} & \multirow[t]{2}{*}{$\begin{array}{c}\text { Predicted } \\
\text { CLABSI }\end{array}$} & \multirow[t]{2}{*}{$\begin{array}{l}\text { Central-Line } \\
\text { Days }\end{array}$} & \multirow[t]{2}{*}{$\begin{array}{c}2020 \text { Q2 } \\
\text { SIR }\end{array}$} & \multirow[t]{2}{*}{$\begin{array}{l}2019 \text { Q2 } \\
\text { SIR }\end{array}$} & \multirow[t]{2}{*}{$\begin{array}{c}\text { SIR \% } \\
\text { Change }^{\mathrm{a}}\end{array}$} & \multirow[t]{2}{*}{$\begin{array}{l}95 \% \text { Confidence Interval } \\
\text { for the } \\
\text { SIR \% Change }\end{array}$} & \multicolumn{6}{|c|}{$\begin{array}{l}\text { Location Type distribution of the } \\
\text { Standardized Infection Ratio (SIR) } \\
\text { for } 2020 \mathrm{Q}^{\mathrm{b}}\end{array}$} \\
\hline & & & & & & & & & $10 \%$ & $25 \%$ & $50 \%$ & $75 \%$ & $90 \%$ & $100 \%$ \\
\hline \multicolumn{15}{|l|}{ Critical care locations } \\
\hline Burn critical care & 51 & 29 & 52.58 & 15,819 & $0.55^{c}$ & $0.44^{c}$ & 25.3 & $(-28.1$ to 120.6$)$ & 0.00 & 0.00 & 0.10 & 0.96 & 1.42 & 2.44 \\
\hline Medical cardiac critical care & 211 & 91 & 87.17 & 81,439 & 1.04 & 1.06 & -1.1 & $(-26.0$ to 32.3$)$ & $\cdots$ & $\ldots$ & $\ldots$ & $\ldots$ & $\ldots$ & $\ldots$ \\
\hline Surgical cardiothoracic critical care & 341 & 116 & 193.66 & 180,522 & $0.60^{c}$ & $0.64^{c}$ & -6.3 & $(-26.9$ to 20.0$)$ & 0.00 & 0.00 & 0.57 & 0.96 & 1.60 & 2.92 \\
\hline $\begin{array}{l}\text { Pediatric surgical cardiothoracic } \\
\text { critical care }\end{array}$ & 44 & 40 & 68.48 & 43,248 & $0.58^{c}$ & $0.50^{c}$ & 16.0 & $(-26.7$ to 84.20$)$ & 0.00 & 0.00 & 0.51 & 0.88 & 1.25 & 2.10 \\
\hline Medical critical care & 584 & 397 & 274.19 & 263,176 & $1.45^{c}$ & 0.91 & $59.6^{d}$ & (35.9 to 87.7$)$ & 0.00 & 0.00 & 1.21 & 2.35 & 2.78 & 7.39 \\
\hline Medical-surgical critical care & 2,076 & 885 & 727.37 & 774,905 & $1.22^{\mathrm{c}}$ & $0.77^{c}$ & $58.9^{d}$ & (42.6 to 77.3 ) & 0.00 & 0.00 & 0.93 & 1.80 & 3.35 & 5.21 \\
\hline Pediatric medical-surgical critical care & 237 & 76 & 106.36 & 70,845 & $0.71^{\mathrm{c}}$ & $0.66^{c}$ & 8.3 & (-20.8 to 47.7$)$ & 0.00 & 0.19 & 0.78 & 1.06 & 1.87 & 2.96 \\
\hline Pediatric medical critical care & 27 & 8 & 5.73 & 3,944 & 1.40 & 1.50 & -6.9 & $(-66.3$ to 156.8$)$ & $\ldots$ & $\ldots$ & $\ldots$ & $\ldots$ & $\ldots$ & $\ldots$ \\
\hline Neurologic critical care & 73 & 21 & 28.58 & 26,628 & 0.73 & 0.73 & 0.4 & ( -46.4 to 88.7$)$ & $\ldots$ & $\ldots$ & $\ldots$ & $\ldots$ & $\ldots$ & $\ldots$ \\
\hline Neurosurgical critical care & 157 & 62 & 67.29 & 61,448 & 0.92 & $0.44^{c}$ & $107.9^{\mathrm{d}}$ & (34.5 to 226.8 ) & $\ldots$ & $\ldots$ & $\ldots$ & $\ldots$ & $\ldots$ & $\ldots$ \\
\hline Surgical critical care & 260 & 136 & 135.29 & 125,839 & 1.01 & 0.93 & 8.6 & $(-14.8$ to 38.3$)$ & 0.00 & 0.00 & 0.81 & 1.20 & 1.96 & 3.56 \\
\hline Trauma critical care & 126 & 48 & 85.99 & 57,473 & $0.56^{c}$ & $0.56^{c}$ & -0.5 & (33.2 to 48.1$)$ & 0.00 & 0.00 & 0.35 & 0.93 & 1.74 & 2.84 \\
\hline \multicolumn{15}{|l|}{ NICU } \\
\hline Neonatal critical care (level II/III) & 514 & 68 & 118.07 & 84,535 & $0.58^{c}$ & $0.66^{c}$ & -13.0 & $(-37.1$ to 20.0$)$ & 0.00 & 0.00 & 0.00 & 0.94 & 1.45 & 2.56 \\
\hline Neonatal critical care (level III) & 330 & 94 & 187.39 & 134,080 & $0.50^{c}$ & $0.63^{c}$ & -20.9 & $(-39.6$ to 3.3$)$ & 0.00 & 0.00 & 0.00 & 0.80 & 1.13 & 1.96 \\
\hline \multicolumn{15}{|l|}{ Wards } \\
\hline Medical ward & 2134 & 251 & 381.28 & 435,198 & $0.66^{c}$ & $0.64^{c}$ & 2.8 & (-13.1 to 21.4$)$ & $\ldots$ & $\ldots$ & $\ldots$ & $\ldots$ & $\ldots$ & $\ldots$ \\
\hline Medical-surgical ward & 3,985 & 346 & 512.83 & 619,386 & $0.67^{c}$ & $0.59^{c}$ & 14.3 & $(-1.3$ to 32.5$)$ & $\ldots$ & $\ldots$ & $\ldots$ & $\ldots$ & $\ldots$ & $\ldots$ \\
\hline Pediatric medical-surgical ward & 564 & 49 & 54.65 & 53,821 & 0.90 & $0.41^{c}$ & $117.6^{\mathrm{d}}$ & (37.1 to 249.5 ) & $\ldots$ & $\ldots$ & $\ldots$ & $\ldots$ & $\ldots$ & $\ldots$ \\
\hline Pediatric medical ward & 180 & 19 & 22.89 & 21,839 & 0.83 & 0.75 & 10.2 & ( -40.4 to 101.9$)$ & $\ldots$ & $\ldots$ & $\ldots$ & $\ldots$ & $\ldots$ & $\ldots$ \\
\hline Surgical ward & 1,168 & 134 & 202.84 & 228,044 & $0.66^{c}$ & $0.60^{c}$ & 10.6 & $(-12.6$ to 40.1$)$ & $\ldots$ & $\ldots$ & $\ldots$ & $\ldots$ & $\ldots$ & $\ldots$ \\
\hline Pediatric surgical ward & 30 & 5 & 6.80 & 6,234 & 0.74 & 0.76 & -3.4 & $(-71.3$ to 198.5$)$ & $\ldots$ & $\ldots$ & $\ldots$ & ... & $\ldots$ & $\ldots$ \\
\hline
\end{tabular}

Note. NICU, neonatal intensive care units.

"Calculated as follows: [(SIR for 2020 Q2 - SIR for 2019 Q2)/SIR for 2019 Q2 × 100].

If there were $<20$ SIRs nationally, the distribution is displayed as missing

'Significantly different from $1 ; P<.05$

${ }^{\mathrm{d}}$ Significant difference between 2020 Q2 and 2019 Q2 SIRs; $P<.05$. 
2020 in 7 regions: Upper Northeast, Lower Northeast, Southeast, Great Lakes, Northern Plains, West, and Northwest. The highest regional 2020 Q2 SIR was 1.07 and occurred in the Upper Northeast, representing a 45\% increase compared to 2019 Q2.

Evaluating by ward type, pediatric medical-surgical wards contributed $4 \%$ of the national central-line days from ward locations in 2020 Q2 and had the greatest change in their SIR (118\% increase) (Table 2). Statistically significant increases in the SIR also occurred in medical critical care (60\%), medical-surgical critical care (59\%), and neurosurgical critical care (108\%). In addition, the device utilization ratio increased in pediatric medical-surgical wards from 0.14 (2019) to 0.18 (2020) (data not shown).

\section{Discussion}

The national SIR for CLABSIs increased significantly by $28 \%$ in 2020 Q2 versus 2019 Q2. During that same time, hospitals were faced with managing the emerging pandemic of COVID-19, which may have played a role in the increase. Infection control practices changed in many healthcare settings during the pandemic to accommodate increasing numbers of patients and to mitigate shortages of personal protective equipment, supplies, and staffing. ${ }^{4}$ Reducing the frequency of contacts with patients and of maintenance activities for central venous catheters (eg, chlorhexidine bathing, scrubbing the hub, site examinations) as well as alterations to processes of care (eg, risking disrupting catheter dressings when placing patients in a prone position) all have the potential to contribute to an increase in CLABSIs. ${ }^{4}$

Consistent with the concern that high-acuity care for patients with COVID-19 posed heightened challenges for preventing device-associated infections; CLABSIs in critical care locations occurred relatively frequently in the 2020 data. The number of CLABSIs in those locations exceeded CLABSIs in ward locations by 1,100 events for the quarter. In prior years, the number of CLABSIs identified in ward locations would typically exceed the number reported from ICUs. ${ }^{2}$ NHSN data do not enumerate the specific type of ICU location of patients with COVID-19, but among all ICUs, increases CLABSIs were highest in the medicalsurgical critical care units. The significant 59\% increase in the 2020 SIR highlights the likely burden that was placed on these units.

The reporting of data on CLABSIs decreased across all regions, with 609 fewer hospitals reporting in 2020 Q2. This drop in reporting may have affected the regional-level analyses because alterations in reporting may have occurred disproportionally in regions with more COVID-19 patients. In particular, even though New York and New Jersey experienced increased hospitalizations during this period, the Middle Northeast region did not demonstrate a significant increase in SIR, and this region had the largest decline in reporting of CLABSIs by $48 \% .{ }^{8}$ In contrast, the Southeast region had only a $12 \%$ drop in reporting of data on CLABSIs to NHSN, and the analyses were able to discern an increase in
CLABSI SIR against the backdrop of an increase in hospitalizations due to COVID-19 during June $2020 .^{8}$

The analysis had several limitations. Results were restricted to locations for which data were consistently reported in both 2019 and 2020 Q2. New locations that may have been created in 2020 in response to patient surge due to the pandemic were not included because they were not present in 2019 for comparison analysis. Restricting the analyses to those units required by CMS HACRP may have excluded other units that were used by hospitals for COVID-19 patients (eg, pulmonary wards).

These findings highlight a substantial increase in CLABSIs in hospitals throughout the United States coinciding with the COVID-19 pandemic. The results of this analysis can be used to understand the increase in HAI burden being placed on the nation's healthcare system and to prioritize ongoing efforts to prevent infections and to drive patient safety.

Acknowledgments. The findings and conclusions in this article are those of the authors and do not necessarily represent the official position of the US Centers for Disease Control and Prevention.

Financial support. No financial support was provided relevant to this article.

Conflicts of interest. All authors report no conflicts of interest relevant to this article.

\section{References}

1. FY 2021 IPPS final rule home page. Centers for Medicare and Medicaid Services website. https://www.cms.gov/medicare/acute-inpatient-pps/fy2021-ipps-final-rule-home-page. Updated January 2021. Accessed February 18, 2021.

2. 2019 National and state healthcare-associated infections progress report. Centers for Disease Control and Prevention website. https://www.cdc.gov/ hai/data/portal/progress-report.html. Published 2020. Accessed February 2, 2021.

3. Kumar G, Adams A, Hererra M, et al. Predictors and outcomes of healthcareassociated infections in COVID-19 patients. Int J Infect Dis 2020;104: 287-292.

4. McMullen KM, Smith BA, Rebmann T. Impact of SARS-CoV-2 on hospitalacquired infection rates in the United States: predictions and early results. Am J Infect Control 2020;48:1409-1411.

5. National Health Safety Network. Bloodstream infection event (central-lineassociated bloodstream infection and non-central-line-associated bloodstream infection) NHSN protocol. Centers for Disease Control and Prevention website. https://www.cdc.gov/nhsn/pdfs/pscmanual/4psc_ clabscurrent.pdf. Updated January 2021. Accessed February 3, 2020.

6. NHSN guide to the SIR. Centers for Disease Control and Prevention website. https://www.cdc.gov/nhsn/pdfs/ps-analysis-resources/nhsn-sirguide.pdf. Updated March 2019. Accessed February 2, 2020.

7. Regional offices. US Department of Health \& Human Services website. https:// www.hhs.gov/about/agencies/iea/regional-offices/index.html. Updated 2014. Accessed February 4, 2021.

8. Sapiano MRP, Dudeck MA, Soe MM, et al. Impact of coronavirus disease 2019 (COVID-19) on US hospitals and patients, April-July 2020. Infect Control Hosp Epidemiol 2021. doi: 10.1017/ice.2021.69. 